Original Research

\title{
Relationships between Plant Communities and Environmental Factors in an Extremely Arid Area: A Case Study in China
}

\author{
XiYi Wang', ${ }^{1,}$ HongBo Ling ${ }^{2 *}$, HaiLiang $\mathrm{Xu}^{2 *}$, CunDe Pan ${ }^{1}$, KaiYe Yuan ${ }^{1}$ \\ 'Xinjiang Agricultural University, Urumqi, Xinjiang, China \\ ${ }^{2}$ Xinjiang Institute of Ecology and Geography, Chinese Academy of Sciences, Urumqi, Xinjiang, China
}

Received: 12 September 2017

Accepted: 18 January 2018

\begin{abstract}
In arid areas, the vegetation is sparse, the ecological environment is fragile, the number of vegetation species is scarce, the community structure is unstable, and the impact of different environmental factors on the plant community is unclear. In this study, the lower reaches of the Tarim River were used as the study area, and the plant community characteristics and environmental factors were investigated. TWINSPAN and CCA were used to undertake a multivariate statistical analysis of vegetation in the region. The objectives of this study were to identify: 1) the optimal vegetation structure for controlling desertification and 2) the key factors affecting vegetation characteristics and the relationship between plants and these key factors. The results showed that the tree-shrub-grass community structure is the most stable and provided the best windbreaks and sand fixing abilities. In addition, attention should be paid to the restoration and reconstruction of herbage when constructing shelter forest. The main environmental factors determining the distribution of plant community types are groundwater depth and soil water content in the lower reaches of the Tarim.
\end{abstract}

Keywords: TWINSPAN, CCA, plant communities, environmental factors, lower reaches of Tarim River

\section{Introduction}

The development of the social economy and the increase in human exploitation and utilization of natural resources has meant that vegetation is widely used by human beings as an important resource. This has led to a series of problems, including vegetation degradation and environmental deterioration [1-2]. In arid areas, natural and artificial disturbance has seriously damaged sparse vegetation, and species diversity has been lost. This has

*e-mail: linghongbo0929@163.com; xuhl@ms.xjb.ac.cn led to ecosystem function degradation, and desertification has become a major environmental problem in arid areas [3-4]. At present, one-fifth of the world's population and one-third of the land is threatened by desertification. To sustainably develop the economy in an arid area, the protection and restoration of vegetation must be strengthened, which means that desertification needs to be curbed. This is of great significance to ecological protection and sustainable economic development in arid areas.

The Tarim Basin, which is located in the hinterland of Eurasia, is a typical arid desert area and an ecologically fragile part of China. The Tarim River is the longest inland river in China, and its basin is characterized by rich 
natural resources and a fragile ecological environment with distinctive geographical features and prominent environmental problems [5]. The lower reaches of the Tarim are located between Daxihaizi Reservoir and Taitema Lake. Populus euphratica is the dominant plant and is mainly distributed on both sides of the river. Tamarix chinensis shrubs are found among Populus euphratica, but its distribution area is wider. Herbaceous plants are mainly distributed near the river [6]. The desert riparian forest, which is sparsely distributed along the lower reaches of the Tarim, is mainly found around $1,000 \mathrm{~m}$ from the river, and shows considerable spatial variability [7]. The vegetated area decreases rapidly as the distance from the river increases, which reflects the adaptability of desert plants to arid climates and the dependence on the river as a water source. The land along the lower reaches of the Tarim mainly includes unused land, forest land, and grassland, and these three land use types account for more than $95 \%$ of the total area of the river basin [8]. Forest land and grassland are important components of desert riparian vegetation, and they play an important role in maintaining the stability of the ecosystem in the lower reaches of the Tarim.

Along the lower reaches of the river, the structure and function of the vegetation are unique because of natural environmental restrictions, such as poor stability and low resistance to interference. Therefore, the vegetation is easily degraded if it is interfered with [9]. Over the past 50 years, human social and economic activities along the river's lower reaches have increased, and water resources development and utilization have increased. This has led to significant changes to natural ecological processes in the watershed [10]. Rivers have been cutoff, lakes have dried up, and the desert riparian vegetation has declined, which has led to desertification and a reduction in biodiversity. Therefore, the lower reaches of the Tarim have become an important ecological and environmental study area in China, and the vegetation community characteristics in this watershed have universal significance for other similar areas around the globe.

The natural oasis ecosystem in the lower reaches of the Tarim has suffered from major vegetation changes, which have been caused by interactions between intrinsic characteristics and external disturbance to the system. There has been no river runoff in the lower reaches of the Tarim, and the river water content mainly depends on a reduced water supply from the Daxihaizi Reservoir water supply. This reduced supply and the cutting off of the river flow are the main reasons for the degradation in natural vegetation [11]. The soil sediment concentration is high, the corrosion resistance is poor, and the scouring effects of the water and wind erosion are relatively strong. These factors have meant that the topography is unstable [12]. Precipitation in the basin is rare, but evaporation is strong, soil texture is poor, the plant material accumulation process is very slow, and productivity is low [13]. In addition, human activity is the fundamental driving force behind natural vegetation degradation, and human disturbance has caused irreversible environmental changes, such as desertification and salinization of the land [14]. The vegetation cannot be restored to the original ecological communities when the situation is so serious.

The implementation of the ecological water transport project has led to a series of changes in the vegetation on both sides of the river along the lower reaches of the Tarim. A large number of endangered plants have begun to recover, and vegetation coverage and species diversity have increased [15]. However, the vegetation community structure is different and the vegetation stability varies in different sections and at different distances from the river. Therefore, it is necessary to find the vegetation structure characteristics that are most stable and have the strongest windbreak and sand fixing abilities. In addition, there are many factors affecting vegetation growth, which means that there is also a need to identify the factors that affect plant growth in the lower reaches of the Tarim. This study identified the most stable plant structure combination to restrain the increasing rate of desertification. In addition, the important factors that affect the vegetation characteristics along the lower reaches of Tarim River were investigated. These results provide a theoretical reference basis that can be used by land managers to make better use of water resources.

\section{Materials and Methods}

\section{Study Area}

The Tarim River is $2,637 \mathrm{~km}$ long and is located in the southern Xinjiang Uygur Autonomous Region. It is the largest inland river in China. The main section of the Tarim River is $1,321 \mathrm{~km}$ long and flows from the confluence of the Akesu, Yerqiang, and Hotan rivers to Taitema Lake. The total area of the basin is $92.06 \times 10^{4} \mathrm{~km}^{2}$ [16]. The lower reaches of the Tarim is the stream segment from Qiala to Taitema Lake, and the main channel is $428 \mathrm{~km}$ long. East of the river is the Kuruk Desert, and the Taklimakan Desert is west of the river. Between the two deserts is the alluvial plain that is part of the lower reaches of the Tarim. The natural vegetation on the alluvial plain contrasts sharply with the surrounding environment, and this "corridor vegetation belt" is also called the "green corridor." The plant species include members of the Salicaceae, Tamaricaceae, Chenopodiaceae, Compositae, Gramineae, and Leguminosae, etc., and they constitute the tree, shrub, and herb communities. The trees are mainly $P$. euphratica, the shrubs are mainly $T$. chinensis, Lycium ruthenicum, and Halimodendron, and the herbs include Phragmites communis, Poacynum hendersonii, Alhagi sparsifolia, Karelinia caspica, and Glyzyrrhiza inflate. However, their growth has declined because of a previous long-term cutoff of the river course. Since the launching of ecological water transportation in 2000 , a large number of dying plants have begun to recover, and vegetation coverage and diversity is rising again. 


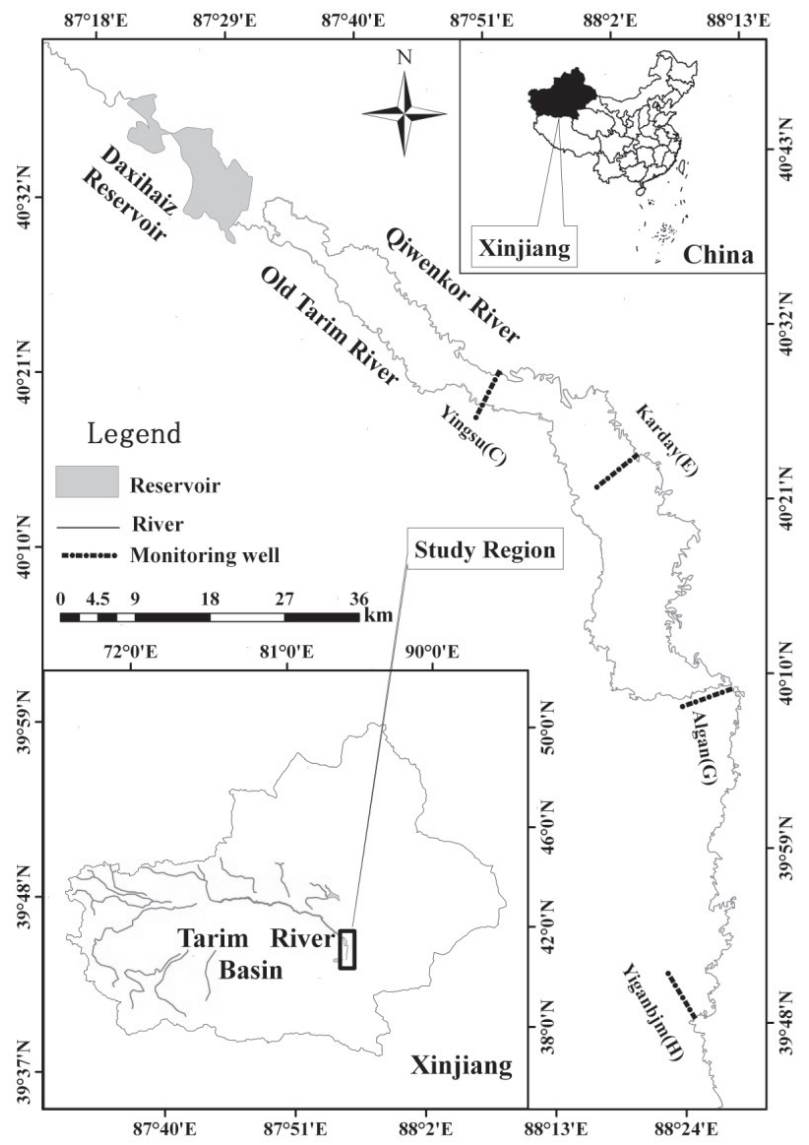

Fig. 1. Layout of sample plots in the lower reaches of the Tarim River.

A large belt of arbor-shrub-grass has appeared on the floodplain and low terraces on both sides of the river.

\section{Field Investigation}

The vegetation in typical sections of the river (Yingsu, Karday, Algan, and Yiganbjm) was surveyed from the end of June to the beginning of July 2017. Fixed sample plots were set up along the lower reaches of the Tarim (Fig. 1). The distance between two adjacent sections was $30-50 \mathrm{~km}$ (Table 1).

In each monitoring section, a transect was placed in a perpendicular direction to the river course. Then a large $50 \times 50 \mathrm{~m}$ quadrat was set up near the monitoring wells, which were $50 \mathrm{~m}$ (ext 50), $150 \mathrm{~m}$ (ext 150), $300 \mathrm{~m}$

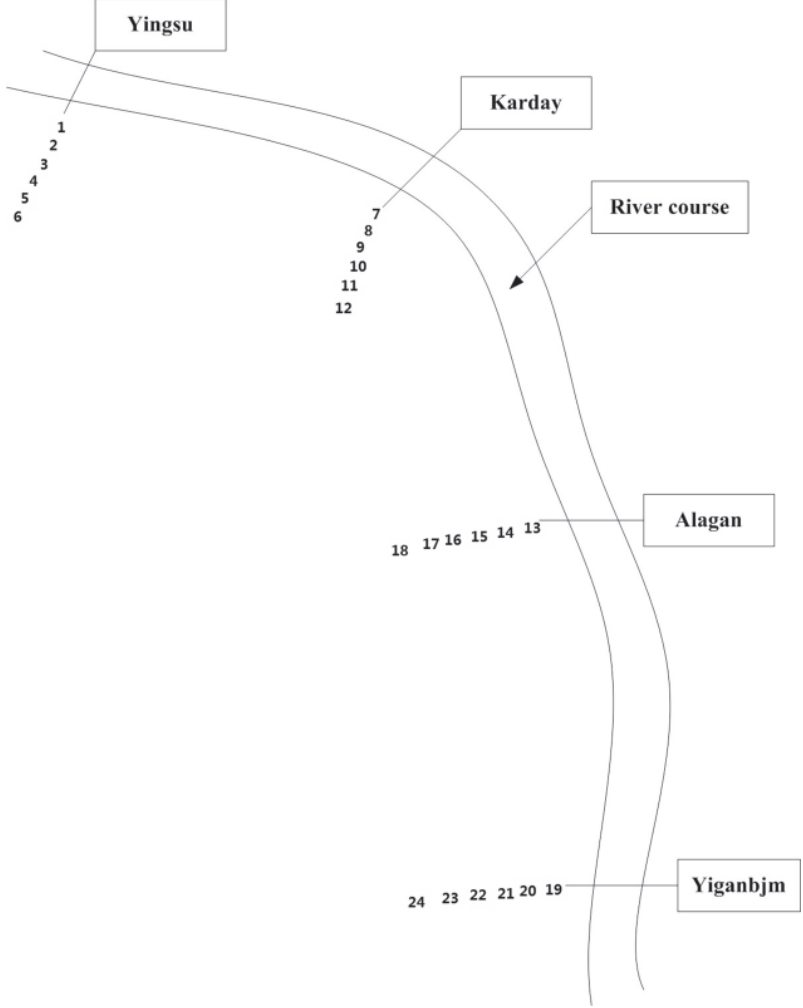

Fig. 2. Sketch map of sample plot numbers in the lower reaches of the Tarim River.

(ext 300), $500 \mathrm{~m}$ (ext 500), $750 \mathrm{~m}$ (ext 750), and 1,050 m (ext 1050) from the river. The GPS position and altitude of each large quadrat was recorded. This meant that 24 large fixed quadrats were set up and numbered (Fig. 2). Then, each large quadrat was divided into four smaller quadrats that were $25 \times 25 \mathrm{~m}$ on average, and indexes, including the individual number, coverage, DBH, basal diameter, height, and crown width of each tree (or shrub) were recorded. Finally, three herbaceous $1 \times 1 \mathrm{~m}$ quadrats were set up in each $25 \times 25 \mathrm{~m}$ quadrat. Then the following parameters were measured: individual number, coverage, height, crown width, and frequency. This meant that 96 tree and shrub quadrats and 288 herbaceous quadrats were completed. In each $50 \times 50$ m quadrat, the surface soil from the upper, middle, and lower points along the quadrat diagonal were taken and mixed. These were then analyzed in the laboratory for soil water content, soil conductivity, and $\mathrm{pH}$ of

Table 1. Environmental characteristics of the 4 typical transects of the lower reaches of the Tarim River.

\begin{tabular}{|c|c|c|c|c|}
\hline Sections & $\begin{array}{c}\text { Distances from Daxihaizi } \\
\text { reservoir } / \mathrm{km}\end{array}$ & Desertification grades & Vegetation coverage $/ \%$ & Degradation degrees \\
\hline Yingsu & 61 & 2.97 & $15-20$ & Mild \\
\hline Karday & 95 & 4.14 & $10-15$ & Moderate \\
\hline Algan & 188 & 5.48 & $7-10$ & Severe \\
\hline Yiganbjm & 284 & 3.87 & $2-7$ & Extreme \\
\hline
\end{tabular}


Table 2. The list of plant species in 24 sites in the lower reaches of the Tarim River Basin.

\begin{tabular}{|c|c|c|c|c|}
\hline No. & Species & Family & Genera & Collection sites \\
\hline 1 & Populus euphratica & Salicaceae & Populus & $1,2,3,7,11,12,13,14,15,19,20,22$ \\
\hline 2 & Tamarix ramosissima & Tamaricaceae & Tamarix Linn. & $\begin{array}{c}1,2,3,4,5,6,7,8,9,11,12,13,16,19 \\
21,23\end{array}$ \\
\hline 3 & Polygonum aviculare & Polygonaceae & Polygonum L. & $2,8,15$ \\
\hline 4 & Nitraria sibirica & Zygophyllaceae & Nitraria L. & $4,9,14$ \\
\hline 5 & Lycium ruthenicum & Solanaceae & Lycium L. & $1,7,13,15,20,21$ \\
\hline 6 & Potentilla chinensis & Rosaceae & Potentilla L. & 15 \\
\hline 7 & Capparis hainanensis & Capparaceae & Capparis Tourn. ex L. & 11,21 \\
\hline 8 & Asparagus persicus & Liliaceae & Asparagus & 16 \\
\hline 9 & Elaeagnus angustifolia & Elaeagnaceae & Elaeagnus & $1,7,13,14,15,22$ \\
\hline 10 & Poacynum hendersonii & Apocynaceae & Poacynum Baill. & 2,13 \\
\hline 11 & Poacynum hendersonii & Apocynaceae & Apocynum & $1,2,3,8,11,17,19,20$ \\
\hline 12 & Cynanchum sibiricum & Asclepiadaceae & Cynanchum Linn. & 20 \\
\hline 13 & Cynanchum sibiricum & Asclepiadaceae & Cynanchum Linn. & 7,13 \\
\hline 14 & Mulgedium tataricum & Compositae & Mulgedium & 12 \\
\hline 15 & Karelinia caspica & Compositae & Karelinia & $2,4,9,13,14,19,20,21,22$ \\
\hline 16 & Inula salsoloides & Compositae & Inula & 19,21 \\
\hline 17 & Taraxacum sp. & Compositae & Taraxacum F. H. Wigg. & 7 \\
\hline 18 & Phragmites communis & Gramineae & Phragmites Adans. & $1,2,5,7,13,15,19,21,22$ \\
\hline 19 & Setaria viridis & Gramineae & Setaria Beauv. & 2,19 \\
\hline 20 & Aelurapus pungens & Gramineae & Aeluropus Trin. & $1,2,12,13,20$ \\
\hline 21 & Astragalus membranaceus & Leguminosae & Astragalus Linn. & 13,21 \\
\hline 22 & Alhagi sparsifolia & Leguminosae & Alhagi Gagneb & $3,4,6,8,9,10,12,16,18,21,23,24$ \\
\hline 23 & Glyzyrrhiza inflate & Leguminosae & Glycyrrhiza Linn. & $5,13,19,22$ \\
\hline 24 & Halimodendron halodendron & Leguminosae & Halimodendron Fisch. ex DC. & $5,8,10,11,17,22,23$ \\
\hline 25 & Sophora apopecuroides & Leguminosae & Sophora & 15,19 \\
\hline 26 & Anabasis aphylla & Chenopodiaceae & Anabasis L. & 20 \\
\hline 27 & Hexinia polydichotoma & Chenopodiaceae & Nitraria & $2,3,7,13$ \\
\hline 28 & Halogeton glomeratus & Chenopodiaceae & Halogeton C. A. Mer. & 1,13 \\
\hline 29 & Kalidium foliatum & Chenopodiaceae & Kalidium Miq & 2,19 \\
\hline 30 & Salsola ruthenica & Chenopodiaceae & Salsola & 16,21 \\
\hline 31 & Salsolacollina & Chenopodiaceae & Salsola & $1,5,13,16$ \\
\hline 32 & Halocnemum strobilaceum & Chenopodiaceae & Halocnemum Bieb. & $14,15,20$ \\
\hline
\end{tabular}

the soil water. Groundwater depth data from 2000 to 2016 were collected, and the average value was calculated. In addition, the groundwater at each monitoring well was extracted and put in a sealed container. These were then taken back to the laboratory for groundwater $\mathrm{pH}$ and mineralization analyses. 
Mathematical Analysis Method:

Two-Way Indicator Species Analysis and Canonical Correspondence Analysis

\section{Two-Way Indicator Species Analysis (TWINSPAN)}

This hierarchical classification is the most effective quantitative community classification method. It can classify the species and the sample plots at the same time. The method first sorts the data by correspondence analysis. Then it obtains the first sort axes, and classifies them after sorting the axes. There is an international general purpose software for two-way indicator species analysis. When there is no sample environmental factor data, then TWINSPAN can analyze the characteristics of the plant communities to determine the relationships between plant distribution and the environment. This analysis is accepted by a majority of plant ecology researchers.

\section{Canonical Correspondence Analysis (CCA)}

This is a ranking method based on correspondence analysis. The method, which is also called "multivariate direct gradient analysis," combines correspondence analysis with multiple regression analysis. Each step of the calculation is regressed with environmental factors. The basic ideas behind CCA is that the iterative process of the correspondence analysis sorts the coordinate values of the quadrat, which are not always available. Then the data is subject to multivariate linear regression with the environmental factors. In other words, $Z_{j}$ is the sorting value of quadrat $\mathrm{j}, b_{0}$ is the intercept, $b_{k}(\mathrm{k}=1$, $2,3 \cdots \mathrm{q}$, where $\mathrm{q}$ is number of environmental factors) is the regression coefficient between the quadrat and environmental factor $k$, and $U_{k j}$ is the observations of environmental factor $k$ in quadrat $j$ :

$$
Z_{j}=b_{0}+\sum_{k=1}^{q} b_{k} U_{k j}
$$

This method first calculates a set of quadrat sorting values and species sorting values. It also carries out a correspondence analysis. Then the quadrat and environmental factor ranks are combined using regression analysis. The obtained quadrat sorting value not only reflects the effects of species composition and the ecological importance of the quadrats on the community, but also the influence of the environmental factors. The sort value of the species is obtained from the weighted average of the quadrat sorting value. The species sort coordinate value is also indirectly associated with environmental factors.

In this study, statistical software WinTWINS 2.3 was used to calculate the TWINSPAN community classification, and analysis software CANOCO 4.5 was used for mapping.

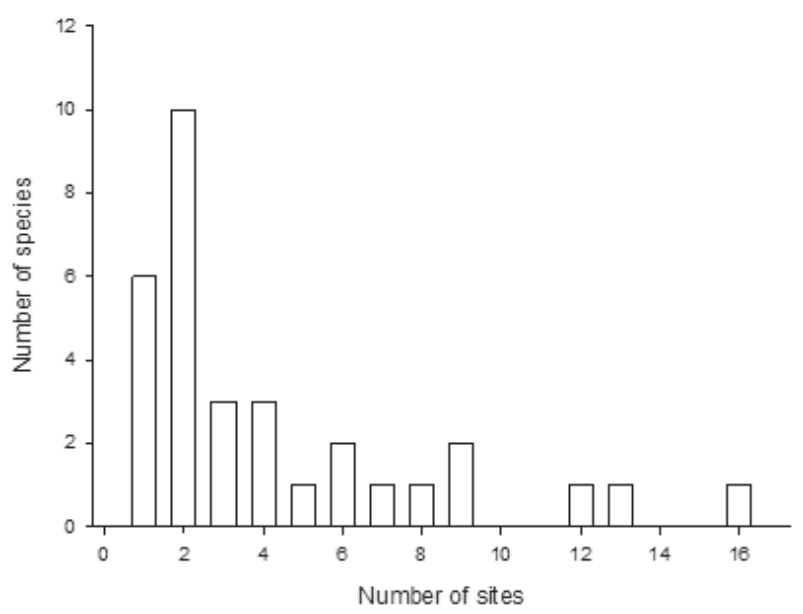

Fig. 3. Pattern of species abundance, presented as number of species plotted against number of collection sites in which a species was found.

\section{Results and Discussion}

\section{Occurrence Frequency of the Plant Species in the Quadrats}

The occurrence frequency of the plant species in the quadrats can reflect the richness of the plant species in the surveyed area. Table 2 shows the plant species that appeared in the quadrats. There were 32 species of plants belonging to 15 families and 30 genera.

Fig. 3 shows the species richness pattern as represented by the number of species against the number of collection sites in which a species was found. This indicates that most of the plant species have a lower frequency of occurrence in quadrats beside the lower reaches of the Tarim. Among the 32 plants species, 6 species only occurred in one quadrat and accounted for $18.75 \%$ of all plants; 10 species occurred in 2 quadrats, and accounted for $6.25 \%$ of all plants; and 3 species occurred in 3 quadrats, which accounted for $9.38 \%$ of all plants. T. chinensis had the highest frequency of occurrence and occurred in 16 quadrats (66.67\% of all quadrats) and 4 transects. The second was $P$. euphratica, which occurred in 13 quadrats (54.17\% of all quadrats). The third was $A$. sparsifolia, which occurred in 12 quadrats (37.50\% of all quadrats).

The frequency of most plant species in the quadrats was low along the lower reaches of the Tarim. This shows that the species richness of this region is poor and the ecosystem is unstable. These results confirm the findings reported by Xi et al. [17] and Chen et al. [18] who also showed that the desert ecosystem in arid and semi-arid areas was more fragile when water and environmental problems are particularly prominent. 


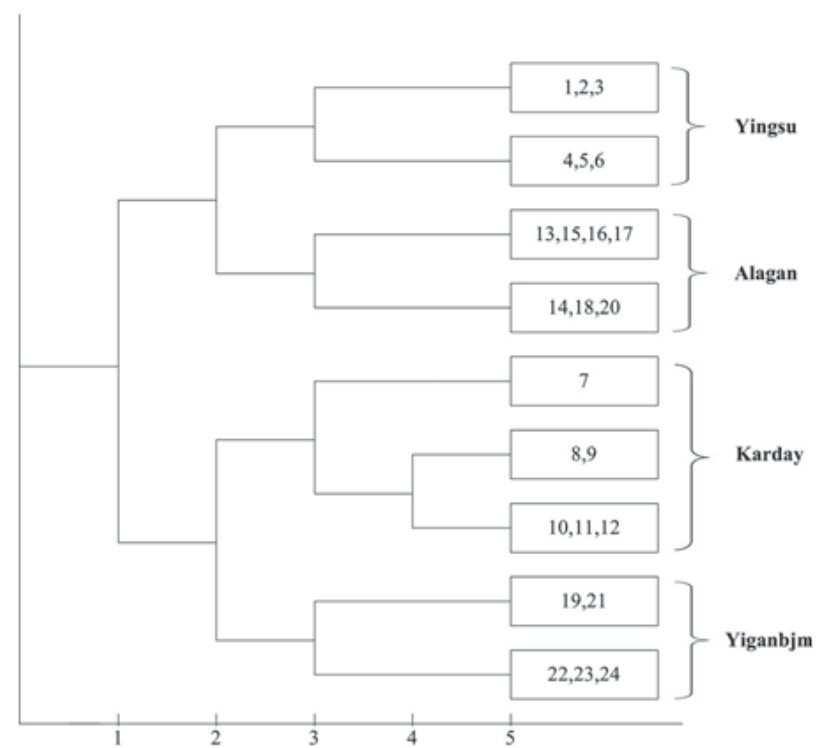

Fig. 4. Graph of TWINSPAN classification for 24 samples in lower reaches of the Tarim River Basin.

\section{Classification of Sample Plots and Species}

In this study, TWINSPAN was used to classify 24 sample plots and 32 plant species. In the division process, all the samples and types are first divided into 2 categories, which were 0 and 1 . Then, these 2 categories were divided into 2 further categories and so on until the required level of division was reached. The division level was up to 7, and the maximum number of categories was 2 each time. The index values of the species in the 24 quadrats were used to create TWINSPAN clustering maps of the quadrats in the lower reaches of the Tarim (Fig. 4).

The right side of Fig. 4 shows the 9 sample types that were divided by TWINSPAN. The classification of the quadrats coincides with the arrangement of the actual sections, except site 20, which should belong to the Yiganbjm section. Therefore, the classification results are mainly in line with the actual situation. Yingsu and Alagan, which belong to the same class, were very different from Karday and Yiganbjm. Yingsu is near the outlet of the Daxihaizi Reservoir and has higher groundwater levels, but Alagan is located at the confluence of the QiwenKor River and Old Tarim River, where the large water inputs lead to higher groundwater levels. There is more vegetation in these 2 sections than at Karday and Yiganbjm. The plant species that most benefit from the improved groundwater levels are $P$. euphratica, Tamarix ramosissima, A. sparsifolia, and Hexinia polydichotoma, which grow well and in large quantities. In addition, other plants, such as $K$. caspica, Halogeton glomeratus, and Glyzyrrhiza inflate, can also be found.

There is a close relationship between Karday and Yiganbjm. The water conditions along the 2 transects are poor, the groundwater level is low, vegetation growth is

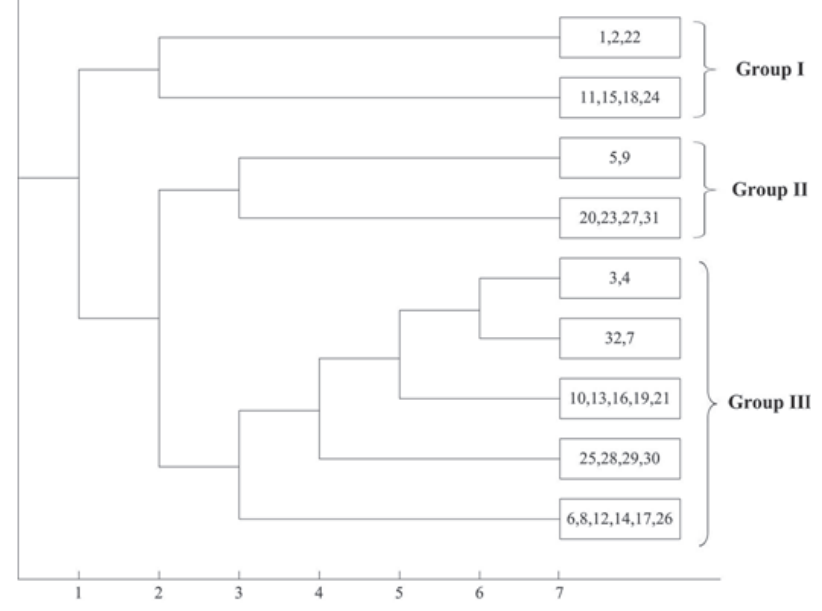

Fig.5. Graph of TWINSPAN classification for 32 species in lower reaches of the Tarim River Basin.

poor, and some of the quadrats are simply large, empty spaces. The constructive species along these 2 transects are $P$. euphratica, T. ramosissima, L. ruthenicum, and A. sparsifolia.

Fig. 4 shows that the quadrats further away from the river are also clearly different from those near the river. Along the Yingsu transect, sample plots 4, 5, and 6 were farther away from the river and were separated at the third divide level from plots 1, 2, and 3, which were near the river. This shows that there are differences among the quadrats as you moved away from the river. The ground surfaces of sample plots 4,5 , and 6 were mainly bare and flat. They contained almost no P. euphratica, and T. ramosissima growth was extremely poor, but there were a few residual roots distributed at the base of the bush fallow. There were also some similar landscapes along other transects.

The right side of Fig. 5 shows the TWINSPAN results that classified the 32 plant species. The plants were divided into 3 species groups. There were 7 species in group I (species 1, 2, 11, 15, 18, 22, and 24), 6 species in group II $(5,9,20,23,27$, and 31$)$, and 19 species in group III $(3,4,6,7,8,10,12,13,14,16,17,19,21,25,26,28,29$, 30 , and 32). The occurrence frequency of most species in group III was low. The TWINSPAN classification was mainly based on plant species data. Therefore, environmental effects were not taken into account.

Figs 4 and 5 suggest that there were many trees and shrubs, including $P$. euphratica, T. chinensis, $H$. halodendron, and L. ruthenicum. Furthermore, herbaceous plants such as $P$. communis, $K$. caspica, A. sparsifolia, and H. glomeratus were common and formed a good tree-shrub-grass structure in Yingsu and Alagan. However, in Karday and Yiganbjm, there were some trees and shrubs such as $P$. euphratica, $T$. chinensis, and $L$. ruthenicum, etc., but there were few herbaceous plants, such as $A$. sparsifolia. Therefore, a tree-shrub structure had formed in these places. According to Zhang [19], the plant community is highly stable and 
has a strong protection ability in Yingsu and Alagan, but the plant community was not so stable in Karday and Yiganbjm. Furthermore, the wind and sand fixing effects suggest that the tree-shrub-grass structure has stronger windbreak and sand fixation abilities than the tree-shrub structure. This confirms the study by Zhou et al. [20]. The tree-shrub structure in Karday and Yiganbjm was similar to that in Yingsu and Alagan, but there were considerable differences in the herbaceous structure. This shows that herbs have a stronger effect on wind and sand fixation, which was similar to the study by Cheng et al. [21]. Therefore, the tree-shrub-grass structure has good windbreak and sand fixation abilities, and the herbs in forests are especially effective as a windbreak and at sand fixation.

\section{CCA Sorting of Sample Plots and Species}

First, the environmental factor data was standardized and the variation characteristics of the environmental factors at different distances from the river in each section were obtained (Fig. 6).

Fig. 6 shows that the altitude decreases as you move downstream. The $\mathrm{pH}$ of the groundwater and soil salinity were not obviously affected by the changes in distance from the river. In each section, the soil water content
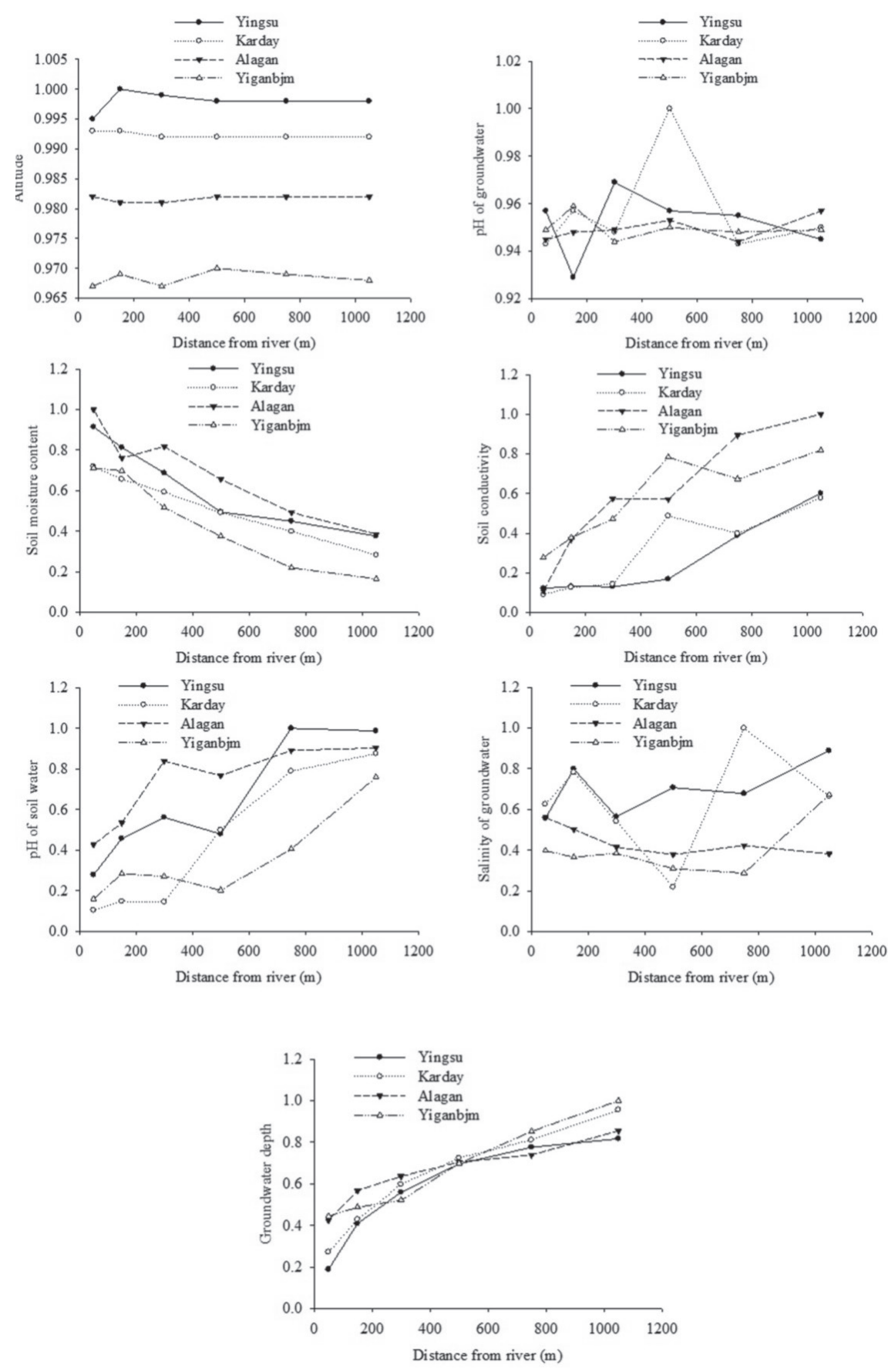

Fig.6. Environmental variables for collection locations standardized by max value. 
Table 3. Correlation coefficients among 7 environmental factors.

\begin{tabular}{|c|c|c|c|c|c|c|c|}
\hline & Altitude & $\begin{array}{c}\mathrm{pH} \text { of } \\
\text { groundwater }\end{array}$ & $\begin{array}{c}\text { Soil water } \\
\text { content }\end{array}$ & $\begin{array}{c}\text { Soil } \\
\text { conductivity }\end{array}$ & $\begin{array}{c}\mathrm{pH} \text { of soil } \\
\text { water }\end{array}$ & $\begin{array}{c}\text { Mineralization of } \\
\text { groundwater }\end{array}$ & $\begin{array}{c}\text { Groundwater } \\
\text { depth }\end{array}$ \\
\hline Altitude & 1 & & & & & & \\
\hline $\mathrm{pH}$ of groundwater & 0.129 & 1 & & & & & \\
\hline Soil water content & 0.193 & -0.074 & 1 & & & & \\
\hline Soil conductivity & $-0.481^{*}$ & 0.015 & $-0.677^{* *}$ & 1 & & & \\
\hline pH of soil water & 0.221 & -0.014 & -0.394 & $0.566^{* *}$ & 1 & & 1 \\
\hline $\begin{array}{c}\text { Mineralization of } \\
\text { groundwater }\end{array}$ & $0.611^{* *}$ & $-0.410^{*}$ & -0.040 & -0.358 & 0.240 & & 1 \\
\hline Groundwater depth & -0.138 & 0.098 & $-0.860^{* *}$ & $0.747^{* *}$ & $0.705^{* *}$ & 0.027 & 1 \\
\hline
\end{tabular}

*Correlation is significant at the 0.05 level (2-tailed)

**Correlation is significant at the 0.01 level (2-tailed)

gradually decreased as the distance from the river increased, whereas the groundwater depth gradually increased; soil electrical conductivity and soil water $\mathrm{pH}$ rose as the distance from the river increased.

In addition, a correlation analysis of the data for 7 environmental factors was carried out (Table 3 ).

Table 3 shows that the soil water content is negatively correlated with groundwater depth $(-0.860)$ and soil conductivity $(-0.677)$. Soil conductivity was also negatively correlated with altitude $(-0.481)$, groundwater salinity (-0.410), and groundwater $\mathrm{pH}(-0.394)$; The salinity of the groundwater had a significant positive correlation with altitude $(0.611)$, soil water $\mathrm{pH}(0.566)$, soil conductivity (0.747), and groundwater depth (0.705). As a result, the water and salt dynamics and their interaction are the main factors that influence environmental factor changes in this area.

Table 3 was taken as the data source for the environment (*.env). In this study, the species coverage, which was used as the growth index for species in the quadrats, was used as the species data source for CANOCO (*.spe).

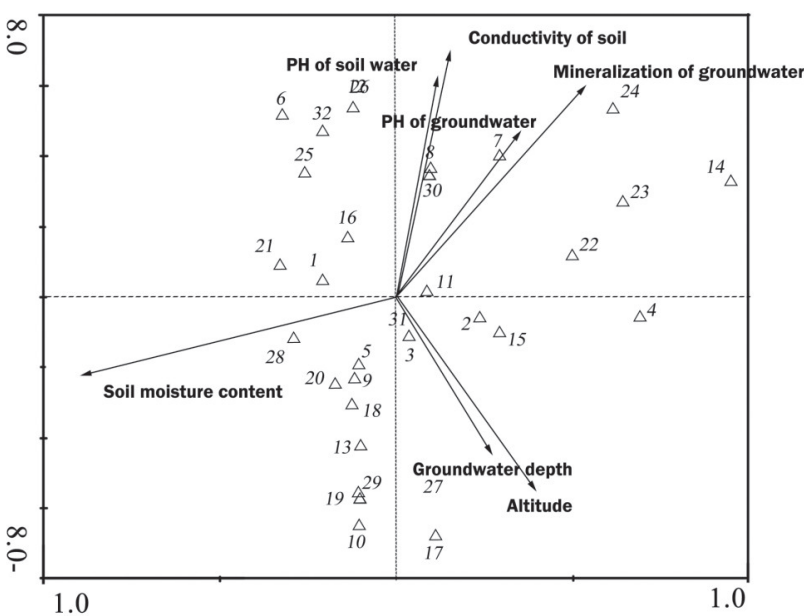

Fig.7. Two-dimensional graph of CCA ordination for plant communities in lower reaches of the Tarim River Basin.
This allowed a data matrix of environmental factors and species to be constructed. Then CCA was used to carry out the sorting analysis of the 32 kinds of plants in the lower reaches of the Tarim River, and a CCA twodimensional sorting map was obtained (Fig. 7).

In Figure 7, " $\Delta$ " represents the species of plants, and the species number is the same as in Table 2. In the sort diagram, environmental factors are represented by the lines with arrows. The length of the line indicates the size of the relationships between plant species and the environmental factors. The angle between the arrow line and the sorting axis indicates the size of the correlation between environment factors and the sort axis. The direction of the line shows the change trend for the environmental factors. In the analysis, when a vertical line links a species with environmental factors, the nearer the intersect of the vertical line and the environment factor distance are to the lines with arrows, the greater the positive correlation between the species and the environmental factor. The further away they are, the more negative the correlation. Fig. 7 shows that individual species - such as 12 and 26, 8 and 30, and 19 and 29 - overlap due to overcrowding.

Plant species and the environmental factor lines reflect the variation in the distribution of plant species along the gradient direction of each environmental factor. The first ordination axis is positively related to groundwater salinity and groundwater $\mathrm{pH}(0.5031$ and 0.4279 , respectively), but is negative correlated with soil moisture content $(-0.4362)$. The second sorting axis was positively related to soil conductivity and soil water $\mathrm{pH}$ ( 0.6745 and 0.5370 , respectively), but was negative related to groundwater depth and altitude $(-0.4671$ and -0.4824 , respectively).

Sixteen plants accounted for $50 \%$ of all species, and they were found in the first and second quadrants. The distribution of these plants decreased as the groundwater depth increased, which indicated that these plants were distributed in areas with shallow groundwater. In the third quadrant, there were 9 species of plants that showed improved growth due to the increase in soil 
water. The fourth quadrant was affected by groundwater and elevation and contained the least number of plants. Therefore, it can be seen that water condition has an important effect on the distribution of plants in the Tarim Basin. In addition, $\mathrm{pH}$, soil conductivity, and salinity also affect the vegetation distribution pattern, and the distribution area of most species increased when $\mathrm{pH}$, soil conductivity, and salinity decreased.

\section{Relationship between Community Distribution and the Main Environmental Factors}

Plant coverage was the index used to investigate the dominant factors affecting vegetation distribution in the area, and a multivariate stepwise regression analysis between coverage by the 32 plant species and 7 environmental factors in 24 sample plots was undertaken. The results show that plant coverage is most closely related to groundwater table depth $(\mathrm{L}, \mathrm{P}<0.01)$ and soil water content $(\mathrm{W}, \mathrm{P}<0.01)$. The stepwise regressions were as follows:

$$
\begin{gathered}
X_{1}=-3.9957 \mathrm{~L}+33.769 \\
\mathrm{R}^{2}=0.7645, \mathrm{~F}=71.421, \mathrm{sig}=0.000, \mathrm{df}=23 \\
X_{2}=37.23 \mathrm{~W}-9.5796 \\
\mathrm{R}^{2}=0.6339, \mathrm{~F}=38.095, \mathrm{sig}=0.000, \mathrm{df}=23
\end{gathered}
$$

The results suggest that groundwater depth is the dominant factor that determines the distribution of the plant communities in the lower reaches of the Tarim River. Furthermore, changes in soil water content also affect plant growth. The distribution patterns of the different plant community types were also affected by topography, geomorphology, temperature, light, and human disturbance, which lead to an increase in the complexity and variability of the vegetation distribution patterns. These results were consistent with the actual distribution of the plant communities and habitat conditions in this region.

In arid areas, the water conditions are an important factor that affects vegetation change [22-24]. Different plant species have different root depths. Therefore, changes in the groundwater depth will directly affect the water absorption range of plant roots, which alters the surface ecological characteristics of vegetation [25]. In addition, the soil water content is also affected by changes in groundwater depth, and this can restrict the growth of plants at the surface [26]. When the groundwater depth is too low, groundwater cannot transport water to the plant roots via capillary action. Therefore, plants with shallower roots die due to a lack of water, and the growth of deep root plants is inhibited [27]. P. euphratica and T. chinensis, for example, can utilize soil water in the 0-100 cm soil layer near the river [28]. However, when they are growing farther from the river, P. euphratica mainly uses groundwater and soil water that is below $120 \mathrm{~cm}$, and the utilization ratio of the groundwater reaches $40-50 \%$, whereas the groundwater utilization rate for $T$. chinensis is up to $95 \%$ [29]. In addition, $P$. euphratica and $L$. ruthenicum seedlings mainly use soil water that is in the $0-20 \mathrm{~cm}$ soil layer, $K$. caspica uses soil water that is in the $50-100 \mathrm{~cm}$ soil layer, and Sophora alopecuroides uses soil water that is in the $5-10 \mathrm{~cm}$ soil layer [30]. Therefore, groundwater and soil water are closely related to plant growth in arid areas, which is consistent with the results produced by this study.

In arid areas, the groundwater depth increases and soil water content decreases with increasing distance from the river [31]. In other words, water conditions become worse as the distance from the river increases. Therefore, the changing characteristics of the vegetation at different distances from the river can reflect the change in water conditions. This study selected the following dominant species: P. euphratica, T. chinensis, $H$. halodendron, A. sparsifolia, K. caspica, P. communis, and $P$. hendersonii. Then the importance values for these species were calculated at different distances from the river (Fig. 8).

Fig. 8, shows that the important values for $H$. halodendron, $K$. caspica, and $P$. communis etc. decreased as distance from the river increased. Up to $500 \mathrm{~m}$ from the river, all of the tree, shrubs, and herbaceous plants assessed were found. When the distance was more than $500 \mathrm{~m}$ away, $P$. euphratica and T. chinensis were the most dominant plants, $A$. sparsifolia was also common, but other species were sparsely distributed. Overall, the soil water content is high and the groundwater depth is close to the surface near the river. Therefore, the trees, shrubs, and herbaceous plants grow well. As the distance from the river increased, soil water content decreased and groundwater depth was lower. The herbaceous plants became scarce, gradually disappeared, and were replaced by $P$. euphratica and T. ramosissima.

These results from the ecological investigation of the plant community and environmental factors in the lower reaches of the Tarim River, combined with

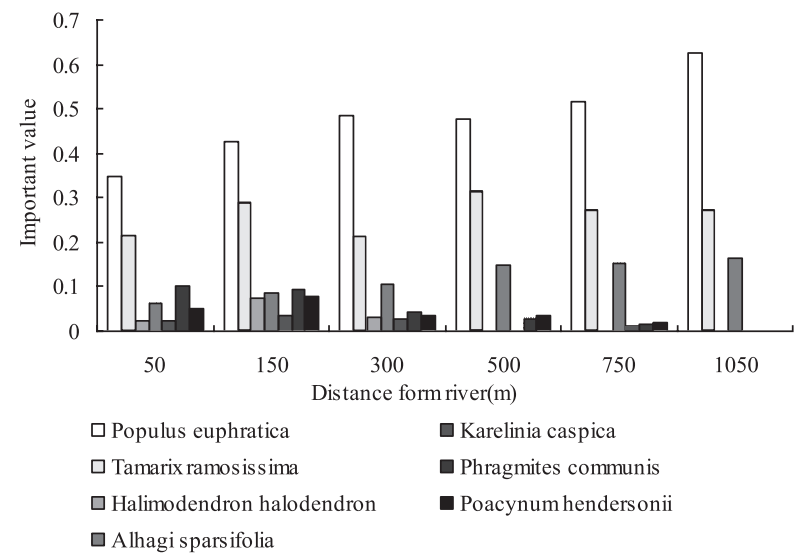

Fig. 8. Variation characteristics of important values of dominant species at different distances from the river. 
the two-way indicator species analysis, show that the optimum community structure to prevent and control desertification was a tree-shrub-grass structure. The herbaceous characteristics in the different areas varied considerably in the lower reaches of the Tarim. The good windbreak performance of the herbs suggests that attention should be paid to restoring herb cover during vegetation ecological construction, which would improve desertification prevention and control. In areas where herbs are rare, such as the Karday and Yiganbjm sections and other similar areas, water diversion irrigation and river flooding can be used, and artificial rain propagation techniques, such as artificial falling water seeding, can be adopted to improve the growth conditions of herbaceous plants. These measures would increase density and coverage by herbaceous plants and lead to a large treeshrub-grass belt. Finally, an effective ecological barrier and sand filter zone that can protect soil stability and sustainable development has already been created in front of the oasis.

The lower reaches of the Tarim are sparsely populated, and there is little industrial activity. At present, the most important project is vegetation and ecological restoration based on river water flow. The key factors affecting the vegetation characteristics are groundwater depth and soil water content in the lower reaches of the Tarim. In previous studies, the relationship between vegetation and water has focused on the changes in vegetation characteristics as varied water levels [32-33]. In the present study, the relationship between vegetation and water has been described quantitatively, and the results show that there is a high correlation between vegetation characteristics and groundwater level and soil water content. As a result, vegetation characteristics can be used as indicators of water conditions (groundwater and soil water) in the lower reaches of the Tarim. Therefore, the main environmental factors mentioned above should be taken into account during the restoration and reconstruction of the damaged ecosystem in the lower reaches of the river. In particular, rational development and utilization of the water resources must be emphasized, and suitable irrigation methods should be used to prevent the decline in the groundwater level and the occurrence of soil salinization.

To date, ecological water transportation has been implemented 18 times in the lower reaches of the Tarim. Generally speaking, there are some changes in the composition and coverage by plant communities during different water transport seasons [34-35]. However, the results of the present study only represent the plant community situation in summer 2017, which means it only covers a small part of the changes in the distribution and composition of plant communities in the lower reaches of the Tarim. Therefore, further studies on the dynamics between plant coverage and composition, and the environmental factors affecting the plant communities in this region need to be undertaken.

\section{Conclusions}

1) There were 32 plant species that belonged to 15 families and 30 genera in the lower reaches of the Tarim River. Furthermore, the frequency of most plant species was very low, which shows that plant species richness was also low in this area. Tamarix chinensis had the highest frequency of occurrence. It was found in 16 sample plots in four transects, which accounted for $66.67 \%$ of all sample plots. The next most frequent were $P$. euphratica and $A$. sparsifolia.

2) The classification of the 24 sample plots and the number of species showed that the 24 sample plots in this region can be divided into 4 groups and 9 types. This analysis was consistent with the physical survey of the 4 transects, and there are also obvious differences among different plot types. Furthermore, the 32 plant species were divided into 3 groups by TWINSPAN, and most of the species in group III were less frequent in the actual sample plots. The quantitative classification results for the sample plots and species showed that the tree-shrub-grass structure had the highest stability, and strongest windbreak and sand fixing capacities. Furthermore, the restoration of windbreak and sand fixing vegetation should focus on the construction of understory herb layers.

3) The most important environmental factors affecting the distribution of the plant communities and the 32 plant species in the lower reaches of the Tarim were groundwater depth and soil moisture content. This study quantitatively revealed the relationship between vegetation characteristics, groundwater depth, and soil water content. The results show that there is a significant correlation between vegetation characteristics and groundwater depth and soil water content. Therefore, the vegetation characteristics can be used as an indicator of water condition changes in the lower reaches of the Tarim River.

\section{Acknowledgements}

This work was jointly supported by the National Natural Science Fund of China (31370551, 41471099) and the Youth Innovation Promotion Association Project (CAS) (2014389). We confirmed that the field study did not involve endangered or protected species. The authors would like to express their cordial gratitude for assistance in this research to XinFeng Zhao and GuangPeng Zhang at the Xinjiang Institute of Ecology and Geography, Chinese Academy of Sciences, Urumqi, China.

\section{Conflict of Interest}

The authors declare no conflict of interest. 


\section{References}

1. TA'ANY R., AMMARI T.G., JIRIES A. Revegetation in Arid Zones: Environmental Impact of Treated Wastewater Irrigation in Al-Karak Province, Jordan. Polish Journal of Environmental Studies. 22 (2), 569, 2013.

2. LI X.B., LI R.H., LI G.Q., WANG H., LI Z.F., LI X., HOU X.Y. Human-induced vegetation degradation and response of soil nitrogen storage in typical steppes in Inner Mongolia, China. Journal of Arid Environments. 124 (1), 80, 2016.

3. BESTELMEYER B.T., OKIN G.S., DUNIWAY M.C., ARCHER S.R., SAYRE N.F., WILLIAMSON J.C., HERRICK J.E. Desertification, land use, and the transformation of global drylands. Frontiers in Ecology \& the Environment. 13 (1), 28, 2016.

4. LAMCHIN M., LEE J.Y., LEE W.K., LEE E.J., KIM M., LIM C.H., CHOI H.A., KIM S.R. Assessment of land cover change and desertification using remote sensing technology in a local region of Mongolia. Advances in Space Research. 57 (1), 64, 2016.

5. WANG Y.F., SHEN Y.J., CHEN Y.N., GUO Y. Vegetation dynamics and their response to hydroclimatic factors in the Tarim River Basin, China. Ecohydrology. 6 (6), 927 , 2013.

6. CHEN Y.N., LI W.H., XU C.C., YE Z.X., CHEN Y.P. Desert riparian vegetation and groundwater in the lower reaches of the Tarim River basin. Environmental Earth Sciences. 73 (2), 547, 2015.

7. ZHU X.C., YUAN G.F., SHAO M.A., YI X.B., DU T. Spatial pattern of riparian vegetation in desert of the lower Tarim River basin. Chinese Journal of Plant Ecology. 39 (11), 1053, 2015 [In Chinese].

8. YANG X.F., WANG X.M., MAO D.L. Mapping Land Use and Land Cover Through MISR Multi-Angle Imagery in the Lower Tarim River. Journal of Jilin University (Earth Science Edition). 46 (2), 617, 2016 [In Chinese].

9. ZHOU H.Y., Zhang X.L., Xu H.L., LING H.B., YU P.J. Influences of climate change and human activities on Tarim River runoffs in China over the past half century. Environmental Earth Sciences. 67 (1), 231, 2012.

10. AISHAN T., ÜMUT H., CYFFKA B., KUBA M., ABLIZ A., BAIDOURELA A. Monitoring the hydrological and ecological response to water diversion in the lower reaches of the Tarim River, Northwest China. Quaternary International. 311 (9), 155, 2013.

11. BAO A.M., HUANG Y., MA Y.G., GUO H., WANG Y.Q. Assessing the effect of EWDP on vegetation restoration by remote sensing in the lower reaches of Tarim River. Ecological Indicators. 74, 261, 2017.

12. ZHU X.C., YUAN G.F., YI X.B., DU T. Quantifying the impacts of river hydrology on riparian vegetation spatial structure: case study in the lower basin of the Tarim River, China. Ecohydrology. 10 (7), 1, 2017.

13. THOMAS F.M., JESCHKE M., ZHANG X., LANG P. Stand structure and productivity of Populus euphratica along a gradient of groundwater distances at the Tarim River (NW China). Journal of Plant Ecology. rtw 078, 2016.

14. AYXAM I., TURSUN Q., ZUMRAT I., MAMUTJAN Q., MNISAHAN T. Influences of Human Activities on the Desertification in the Lower Reaches of Tarim River. Research of Soil \& Water Conservation. 18 (1), 56, 2011 [In Chinese].
15. SUN Z., CHANG N.B., OPP C., HENNIG T. Evaluation of ecological restoration through vegetation patterns in the lower Tarim River, China with MODIS NDVI data. Ecological Informatics. 6 (2), 156, 2011.

16. LIU Y.L. Report on filed survey of middle and lower reaches of Tarim river. Beijing: China Statistics Press. 22, 2000 [In Chinese].

17. XI H.Y., FENG Q., ZHANG L., SI J.H., CHANG Z.Q., YU T.F., GUO R. Effects of water and salinity on plant species composition and community succession in Ejina Desert Oasis, northwest China. Environmental Earth Sciences, 75 (2), 1,2016

18. CHEN Y.N., LI W.H., ZHOU H.H., CHEN Y.P., HAO X.M., FU A.H., MA J.Y. Experimental study on water transport observations of desert riparian forests in the lower reaches of the Tarim River in China. International Journal of Biometeorology, 61 (1), 1, 2017.

19. ZHANG P., XU H.L., LING H.B., ZHAO X.F., ZHANG P.. Variation of Vegetation Communities under Different Flooding Frequency in the Lower Reaches of the Tarim River. Arid Zone Research. 33 (6), 1242, 2016 [In Chinese].

20. ZHOU H.H., LI W.H., LENG C., CAO Z.C., WANG J., WANG H.J. Effect of environmental and ecological function of shelterbelts in oasis -desert ecotone of the lower Tarim River. Arid Land Geography. 35 (1), 82, 2012 [In Chinese].

21. CHENG H., LI X., MA L.J., LIU G. Investigation and analysis on protective effects of different covers vegetation on ground in the lower reaches of the Tarim River. Arid Land Geography. 31 (3), 373, 2008 [In Chinese].

22. CURRELL M.J., DAHLHAUS P., LI H. Stable isotopes as indicators of water and salinity sources in a southeast Australian coastal wetland: identifying relict marine water, and implications for future change. Hydrogeology Journal. 23 (2), 235, 2015.

23. SUN Z.Y., XIANG L., RUI M. Water uptake by saltcedar (Tamarix ramosissima) in a desert riparian forest: responses to intra-annual water table fluctuation. Hydrological Processes. 30 (9), 1388, 2016.

24. PESSARAKLI M. Saltgrass, a Minimum Water and Nutrient Requirement Halophytic Plant Species for Sustainable Agriculture in Desert Regions. 2 (1), 21, 2016.

25. VERVOORT R.W., SEATM V.Z. On stochastic modelling of groundwater uptake in semi-arid water-limited systems: root density and seasonality effects. Ecohydrology. 5 (5), $580,2012$.

26. SOYLU M.E., KUCHARIK C.J., II S.P.L. Influence of groundwater on plant water use and productivity: Development of an integrated ecosystem - Variably saturated soil water flow model. Agricultural \& Forest Meteorology. 189-190 (6), 198, 2014.

27. ZHU L., XU X., MAO G.L. Water sources of shrubs grown in the northern Ningxia Plain of China characterized by shallow groundwater table. Chinese Journal of Plant Ecology. 36 (7), 618, 2012 [In Chinese].

28. CENG Q., MA J.Y. Plant Water Sources of Different Habitats and Its Environmental Indication in Heihe River Basin. Journal of Glaciology and Geocryology. 35 (1), 148, 2013 [In Chinese].

29. ZHOU T.H., ZHAO C.Y., WU G.L., JIANG S.W., YU Y.X., WANG D.D. Application of Stable Isotopes in Analyzing the Water Sources of Populus euphratica and Tamarix ramosissima in the Upstream of Tarim River. Journal of Desert Research. 37 (1), 124, 2017 [In Chinese]. 
30. CHEN X.L., CHEN Y.N., CHEN Y.P. Relationship among water use of different plants in Heihe River riparian forests. Chinese Journal of Eco-Agriculture. 22 (8), 972, 2014 [In Chinese].

31. WU X.M., TIYIP T., SAWUT M., SUN Q., JIANG H.T., ZHANG F. Spatial variability of soil moisture in typical oasis of different seasons in arid areas :a case of Yutian Oasis. Arid Land Geography. 37 (2), 349, 2014 [In Chinese].

32. ZHANG X.Q., CHEN Y.N., LI W.H., YU Y., SUN Z.H. Restoration of the lower reaches of the Tarim River in China. Regional Environmental Change. 13 (5), 1021, 2013.

33. HAO X.M., LI W.H. Impacts of ecological water conveyance on groundwater dynamics and vegetation recovery in the lower reaches of the Tarim River in northwest China. Environmental Monitoring \& Assessment. 186 (11), 7605, 2014.

34. GUPTA G.P. Deposition and Impact of Urban Atmospheric Dust on Two Medicinal Plants during Different Seasons in NCR Delhi. Aerosol \& Air Quality Research. 16, 2920, 2016.

35. STUEPP C.A., WENDLING I., KOEHLER H.S., ZUFFELLATO R.K.C. Quality of clonal plants of Piptocarpha angustifolia in different renewable substrates and seasons of the year. Pesquisa Agropecuaria Brasileira. 51 (11), 1821, 2016 